\title{
CONTRIBUIÇÕES DO PROJETO DE EDUCAÇÃO AMBIENTAL “CLUBE TETÉIA" DA FUNDAČ̃̃o PARQUE ZOOLÓGICO DE SÃO PAULO PARA O ENVELHECIMENTO ATIVO E A INCLUSÃO SOCIAL DE IDOSOS
}

Kátia G. de Oliveira Rancura ${ }^{1}$ Lilian O. Rocha ${ }^{2}$ Bruna Toricelli ${ }^{3}$

Camila Martins ${ }^{4}$

Caio H. Araújo-Bissa ${ }^{5}$

Resumo: O presente artigo tem como objetivo trazer reflexões sobre projeto de educação ambiental "Clube Tetéia" da Fundação Parque Zoológico de São Paulo a partir das percepções apresentadas pelas idosas participantes, no sentido de compreender suas potencialidades para a realização de práticas reflexivas e críticas de educação ambiental que valorizem a atuação, a troca de saberes e o envelhecimento ativo dos idosos. A pesquisa apresentou uma abordagem qualitativa, na qual 16 idosas participaram de questionários aplicados durante a edição 2014 do Clube Tetéia. Dentre os resultados, destacamos o potencial de tal projeto para o processo de ensino-aprendizagem das participantes, além de sua contribuição para a inserção dos idosos na sociedade e na tomada de decisões acerca de questões ambientais.

Palavras-chave: Educação Ambiental; Práticas Educativas Intergeracionais; Idosos; Envelhecimento Ativo.

\footnotetext{
${ }^{1}$ Divisão de Educação e Difusão - Fundação Parque Zoológico de São Paulo. Email: krancura@sp.gov.br 2 Programa de Pós-Graduação em Manejo e Conservação da Fauna Silvestre - Universidade de Santo Amaro. E-mail: oliveira.lilianrocha@gmail.com

${ }^{3}$ Programa de Pós-Graduação em Conservação da Fauna (UFSCar/FPZSP). bu.toricelli@gmail.com

${ }^{4}$ Divisão de Educação e Difusão - Fundação Parque Zoológico de São Paulo. Email: martinsca@usp.br

${ }^{5}$ Mestre em Conservação da Fauna (UFSCar/FPZSP). Email: caiohabissa@gmail.com.
}

Revbea, São Paulo, V. 11, No 4: 269-288, 2016.

revista brasileira educação ambiental 


\section{Introdução}

Em vários países, as populações estão envelhecendo. No Brasil, o ritmo de crescimento da população idosa tem sido sistemático e consistente (IBGE, 2010) e, segundo a Organização Mundial da Saúde (OMS), até 2025 o país será o sexto do mundo em número de idosos. Este aumento da longevidade da população, no entanto, precisa ser acompanhado pela melhoria ou manutenção da saúde e qualidade de vida (WORLD HEALTH ORGANIZATION, 2005).

A OMS tem apoiado o desenvolvimento de projetos que promovam o envelhecimento ativo da população, que consiste no processo de otimização das oportunidades de saúde, participação e segurança, com o objetivo de melhorar a qualidade de vida à medida que as pessoas ficam mais velhas. $O$ envelhecimento ativo permite que as pessoas percebam o seu potencial para 0 bem-estar físico, social e mental ao longo do curso da vida, e que participem da sociedade de acordo com suas necessidades, desejos e capacidades. A palavra "ativo" refere-se à participação contínua nas questões sociais, econômicas, culturais, espirituais e civis, e não somente à capacidade de estar fisicamente ativo ou de fazer parte da força de trabalho (WORLD HEALTH ORGANIZATION, 2005).

Nesse contexto, na Política Nacional do Idoso (BRASIL, 1994) há um destaque para a necessidade de promover atividades, projetos, cursos, ações e espaços educativos em que os idosos possam estar inseridos, contribuindo para o diálogo entre gerações e para o envelhecimento ativo e saudável (PEREIRA et al., 2006), em espaços escolares e não escolares da sociedade. Para Machado, Velasco e Amim (2006), atividades como centros de convivência, oficinas, cursos, universidades abertas e outras iniciativas da comunidade podem integrar o idoso na sociedade contemporânea, valorizando seus saberes e suas vivências para repensar o nosso modo de agir e pensar em estratégias para a conservação dos recursos naturais, trazendo maior qualidade de vida (CASSOL, 2012) e um envelhecimento ativo e participativo.

Dentre as ações existentes destinadas aos idosos, destacamos a relevância de um projeto educativo criado no âmbito do Programa de Educação Ambiental da Fundação Parque Zoológico de São Paulo (FPZSP), intitulado "Clube Tetéia", o qual é de extrema originalidade por promover a inclusão e valorização dos saberes dos idosos relacionados com as atividades do zoológico, permitindo a interação entre a equipe educadora, a equipe técnica e o público idoso na discussão de temáticas sobre conservação da biodiversidade.

Tal ação educativa foi desenvolvida a partir da perspectiva de que a promoção de estratégias que valorizem e proporcionem qualidade de vida, bem-estar e um envelhecimento ativo aos idosos está intrinsicamente relacionada com as questões ambientais. Diante do contexto socioambiental em que vivemos, marcado por uma série de transformações políticas, econômicas, tecnológicas, culturais e sociais que por muitas vezes são sinônimos de uma era de grande distanciamento do ser humano com a 
natureza, a participação, o diálogo e a inclusão social é um dos caminhos para construirmos sociedades sustentáveis. É nesse aspecto que ressaltamos a importância das práticas e ações de educação ambiental (EA) em todas as esferas da sociedade, em seus diversos contextos.

Um grande marco mundial relacionado à preocupação com as questões socioambientais e que culminou em relevantes documentos oficiais foi a Conferência das Nações Unidas sobre o Meio Ambiente e Desenvolvimento (Rio - 92), na qual participaram mais de 170 países. Dentre estes documentos está o Tratado de Educação Ambiental para Sociedades Sustentáveis.

Após esse grande marco, diversos países iniciaram a construção de suas próprias legislações e documentos oficiais sobre políticas e diretrizes ambientais e, no âmbito nacional, temos em 1999 a criação da Política de Educação Ambiental (PNEA, lei no 9.795) que dispõem em seus artigos que a EA é "o processo por meio do qual o indivíduo e a coletividade constroem valores sociais, conhecimentos, habilidades, atitudes e competências voltadas para conservação ambiental" (BRASIL, 1999). Essa Política destaca a importância de ações individuais e coletivas para a superação do atual contexto socioambiental, enfatizando a necessidade do diálogo intergeracional e da valorização dos saberes e das memórias na construção de sociedades sustentáveis. É nesse aspecto que identificamos a importância da pluralidade de saberes e vivências de diversos atores e contextos sociais para abordar temáticas ambientais de forma reflexiva, crítica e transformadora.

Diante da importância da formação de redes de interações e participações entre todos os níveis sociais para fortalecer as ações educativas e as tomadas de decisões de forma crítica, a qual está destacada na PNEA (Brasil, 1999) e no Tratado de Educação Ambiental para Sociedades Sustentáveis e Responsabilidade Global (RIO DE JANEIRO, 1992), observamos uma grande aproximação com a Política Nacional do Idoso (Lei no 8842 de 1994), uma vez que esta traz como objetivo "assegurar os direitos sociais do idoso, criando condições para promover sua autonomia, integração e participação efetiva na sociedade", enfatizando no Artigo $4^{\circ}$ a "viabilização de formar alternativas de participação, ocupação e convívio do idoso, que proporcionem sua integração às demais gerações" (BRASIL, 1994).

Em um contexto socioambiental em que há uma necessidade de transformação de valores sociais, éticos, estéticos e políticos, os idosos têm muito a contribuir, permitindo uma troca de conhecimentos que considere suas vivências, histórias e memórias da sua relação com 0 ambiente natural. Compreender como os seres humanos se relacionavam no passado é de extrema importância para estabelecer novos olhares e maneiras de visualizar o futuro e, nesse sentido, a memória e a contribuição dos saberes dos idosos é de uma riqueza inigualável (MACHADO, VELASCO, AMIM, 2006). Para esses mesmos autores, os idosos que viveram essas transformações ambientais podem cooperar com informações que serão imprescindíveis para definir estratégias e novos caminhos para uma sociedade sustentável. 
Dias e Pieper (2013) desenvolveram uma pesquisa com idosos agricultores de uma região do Rio de Janeiro para compreender a importância desses sujeitos na identificação dos problemas socioambientais a partir da sua vivência, das suas lembranças e memórias e dos conhecimentos locais, com o objetivo de auxiliarem nas decisões da construção de práticas mais sustentáveis sobre aquele ambiente. Os autores destacam que as histórias relatadas pelos idosos permitiram identificar o processo de desmatamento que foi intensificado nos últimos anos, além de ter contribuído para o levantamento e mapeamento dos recursos hídricos da região. Essa pesquisa exemplifica a importância de desenvolver ações educativas, projetos e pesquisas que valorizem os saberes dos idosos de forma articulada com as questões ambientais.

Com base no repertório teórico apresentado, o presente artigo tem como objetivo trazer reflexões sobre os pontos fortes, as oportunidades e os desafios do projeto educativo "Clube Tetéia" da Fundação Parque Zoológico de São Paulo a partir das percepções apresentadas pelas idosas participantes ao longo das atividades desenvolvidas na edição do ano de 2014, no sentido de contribuir para o aprimoramento de práticas reflexivas e críticas de educação ambiental que valorizem a atuação, a troca de saberes e o envelhecimento ativo dos idosos.

\section{Caminhos metodológicos}

\section{Caracterização do projeto de educação ambiental "Clube Tetéia" da Fundação Parque Zoológico de São Paulo}

Ao redor do mundo há muitos parques, reservas naturais, atrativos turísticos, zoológicos e safáris que já promovem a inclusão do público idoso em suas atividades, seja como visitante ou ainda como voluntário, funcionário ou agente de serviço comunitário.

O Programa de Educação Ambiental da Fundação Parque Zoológico de São Paulo também vem trabalhando há algum tempo com propostas que contemplem práticas inclusivas, porém busca aprimorá-las continuamente e incluir cada vez mais pessoas, com diferentes necessidades, já que uma iniciativa completa de inclusão deve considerar todas as minorias sociais, sejam deficientes, idosos, carentes de recursos financeiros, grupos em risco social, entre outros.

Nesse sentido, após analisar os resultados positivos obtidos em oficinas realizadas com idosos em um projeto educativo desenvolvido durante 0 ano de 2012 na FPZSP (LEITE, 2012) e o grande interesse demonstrado pelos participantes em continuar integrando ações como essa, foi elaborada a proposta de criação de um Clube para idosos dentro da FPZSP, onde pudessem ser abordados assuntos relacionados ao cotidiano de um zoológico e ao seu papel conservacionista, visando estimular os participantes a refletirem sobre diversas questões ambientais, contribuindo para torná-los agentes 
multiplicadores dessas informações, além de proporcionar trocas intergeracionais entre os envolvidos.

O Clube Tetéia, como foi chamado em homenagem a uma fêmea de hipopótamo que viveu por muitos anos na FPZSP e atingiu o bem estar na velhice, passou a integrar o Programa de Educação Ambiental do Zoológico em 2013 e recebeu o apoio do Curso de Gerontologia da Escola de Artes, Ciências e Humanidades da Universidade de São Paulo (EACH/USP) e da Universidade Aberta da Terceira Idade (UnATI). A atividade consiste em encontros quinzenais, com três horas de duração, entre um grupo de até 20 idosos participantes, profissionais de diferentes áreas do Zoológico e educadores do parque, que realizam a mediação desse processo (RANCURA et al., 2013). As atividades desenvolvidas nesses encontros, elaboradas pela equipe de cada área convidada a participar, procuram abordar questões relacionadas ao cotidiano da FPZSP e à conservação da fauna silvestre, por meio de atividades teóricas e práticas, como visitas às áreas técnicas e de exposição do zoológico e a realização de oficinas e dinâmicas de grupo (Figura 1).
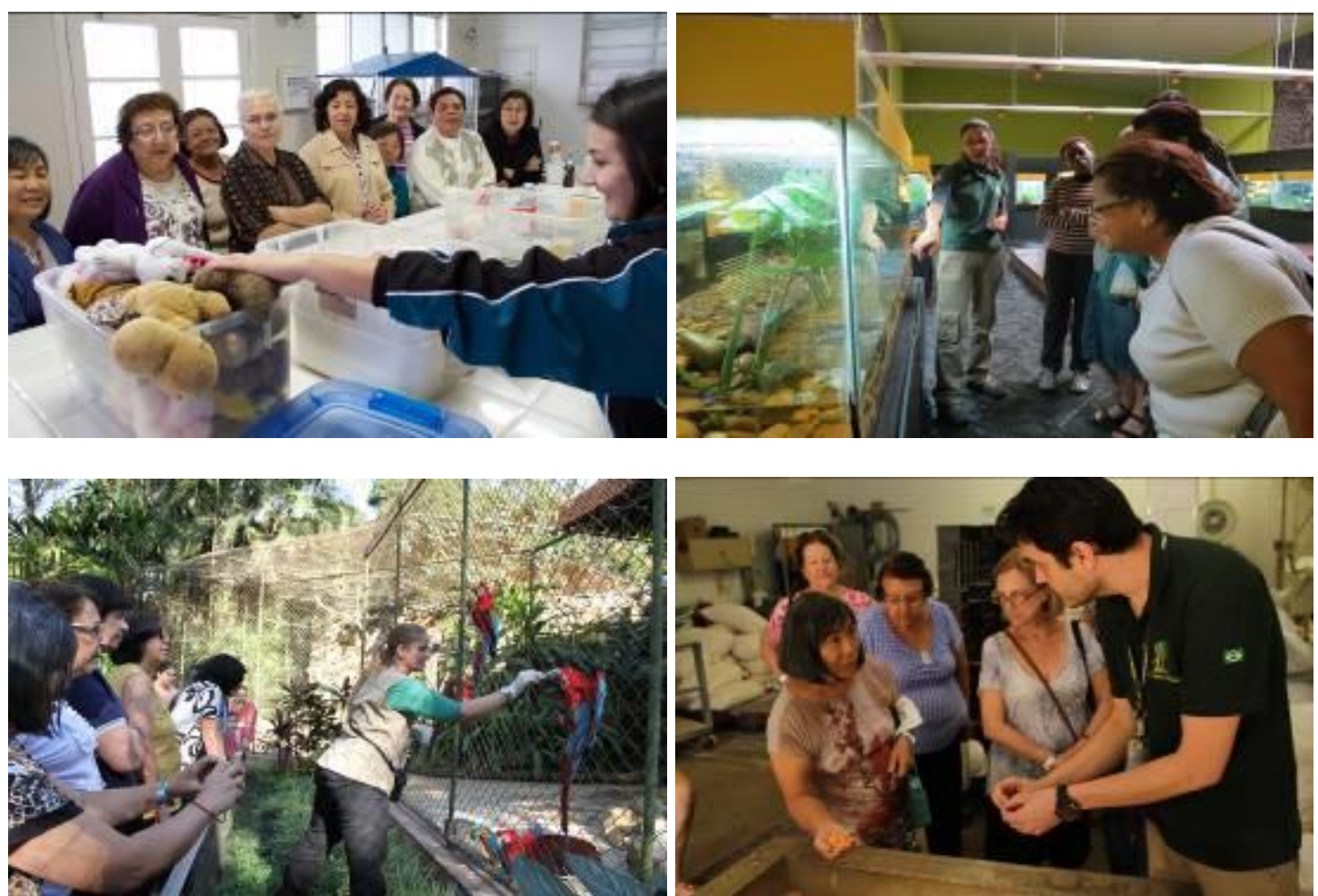

Figura 1: Exemplos de alguns encontros realizados pelos seguintes setores: Mamíferos, Répteis, Aves e Alimentação Animal.

Fonte: Paulo Gil/ Arquivo Fundação Parque Zoológico de São Paulo 


\section{Caracterização do público participante da pesquisa}

No Clube Tetéia - Edição 2014 tivemos a participação de 16 idosas, as quais participaram do processo de coleta de dados desta pesquisa. Em relação à faixa etária, todas elas apresentam idade superior a 60 anos e, de acordo com a World Health Organization (2005), as mulheres vivem mais do que os homens na maioria dos países, fato que reflete na maior taxa de mulheres por homens em grupos etários mais velhos. Tal afirmação pode ser um dos motivos para a participação dominante desse gênero na atividade.

A grande maioria das idosas é aposentada e possuem nível de escolaridade variado, desde o ensino fundamental incompleto até o superior completo. Quanto ao local onde vivem, praticamente todas são originárias da Zona Leste da cidade de São Paulo, o que já era esperado, pois muitas fazem parte do projeto Universidade Aberta à Terceira Idade (UnATI) da Universidade de São Paulo, localizada nesta mesma região. Levam em média 1h30min para chegarem à FPZSP, utilizando o transporte público para seu deslocamento.

\section{Abordagem qualitativa da pesquisa}

A pesquisa teve abordagem qualitativa, a qual possibilita um contato direto com a situação investigada, dando maior ênfase ao processo que ao produto da pesquisa (LUDKE; ANDRÉ, 1986; TRIVIÑOS, 1987).

A coleta de dados foi realizada a partir de dois questionários, um aplicado no início das atividades do Clube Teteia e outro no último encontro do ano. O primeiro tinha o objetivo de compreender o motivo pelo qual quiseram participar do Clube Teteia, se já tinham participado de outras atividades de educação ambiental e visitado outros zoológicos ou aquários. Além disso, as idosas foram questionadas quanto ao seu conhecimento sobre a função dos zoológicos e solicitadas a descreverem a educação ambiental em cinco palavras.

O segundo questionário tinha como foco entender as características e o processo educativo que vivenciaram no Clube Tetéia - Edição 2014, procurando compreender as potencialidades e desafios do programa e sua contribuição para a transformação da vida das participantes. Além disso, questionamos se as atividades realizadas lhes fizeram recordar alguma de suas experiências, como foi a troca de conhecimentos com a equipe do Zoológico e, finalmente, se indicariam o Clube Teteia para outras pessoas.

Os dados obtidos na pesquisa foram analisados a partir da Análise Textual Discursiva (MORAES, 2007). Considerada por este autor um processo emergente de compreensão, é realizada em um ciclo iniciado pela desmontagem dos textos ou unitarização, na qual o texto é examinado detalhadamente; seguida do estabelecimento de relações, em um processo de categorização das unidades obtidas; e da construção de um metatexto, no qual são combinadas descrição e interpretação, culminando na teorização sobre o fenômeno estudado. 


\section{Resultados e discussão}

Com o objetivo de compreender as percepções das idosas participantes do Clube Tetéia - Edição 2014, tendo como base as técnicas de coleta de dados apresentadas anteriormente, iniciaremos as reflexões dos resultados obtidos a partir da apresentação de informações sobre as concepções de educação ambiental, as visões a respeito da função dos zoológicos e as expectativas a priori sobre o Clube Tetéia. Em seguida, faremos uma descrição sobre a sequência de atividades desenvolvidas ao longo do ano de 2014. Por fim, apresentaremos os resultados do questionário aplicado ao final de todo o processo educativo, visando observar a percepção das participantes em relação às atividades e à contribuição do Clube Tetéia para uma maior inclusão e transformação na qualidade de vida dos idosos.

\section{Concepções sobre educação ambiental, funções dos zoológicos e as expectativas apresentadas pelas participantes do Clube Tetéia - Edição 2014.}

No questionário aplicado no primeiro encontro do Clube Tetéia, tínhamos o objetivo de compreender as expectativas das participantes diante de sua inserção no Clube, se já haviam participado de atividades de educação ambiental, quais suas percepções sobre esse campo do conhecimento e, por fim, quais as suas visões sobre a função dos zoológicos.

O primeiro questionamento realizado foi "Quais são suas expectativas sobre o Clube Tetéia?" Na Tabela 1 podemos observar as principais categorias emergentes sobre essa temática.

Tabela 1: Questionamento sobre principais expectativas em relação ao Clube Tetéia. Quais são suas expectativas sobre o Clube Tetéia?

\begin{tabular}{|c|c|c|}
\hline $\begin{array}{l}\text { Frequência } \\
\text { de respostas }\end{array}$ & Categorias & Exemplos de citações \\
\hline 9 & $\begin{array}{l}\text { Aprendizagem } \\
\text { sobre questões } \\
\text { ambientais }\end{array}$ & $\begin{array}{c}\text { "Momentos de aprendizagem com biólogos e } \\
\text { tratadores funcionários do zoológico e convívio e } \\
\text { entretenimento com pessoas interessadas na vida dos } \\
\text { animais" Participante } 2 \text {. } \\
\text { "Ter mais conhecimento sobre o meio ambiente e os } \\
\text { animais" Participante } 4 \text {. }\end{array}$ \\
\hline 2 & $\begin{array}{l}\text { Aprendizagem } \\
\text { sobre educação } \\
\text { ambiental }\end{array}$ & $\begin{array}{l}\text { "Melhorar meu conhecimento com Educação } \\
\text { Ambiental" Participante } 10 . \\
\text { "(...) adquirir conhecimento sobre a educação } \\
\text { ambiental" Participante } 12 .\end{array}$ \\
\hline 1 & $\begin{array}{l}\text { Momentos de } \\
\text { descontração }\end{array}$ & $\begin{array}{c}\text { "(...) fazer amigos e passar horas agradáveis" } \\
\text { Participante } 6 .\end{array}$ \\
\hline
\end{tabular}

Fonte: Autoria própria. 
Ao observar esses dados, percebemos que a maioria das participantes respondeu que a principal expectativa era contribuir para a aprendizagem de conhecimentos relacionados às temáticas ambientais e aos princípios de educação ambiental.

De acordo com Scortegagna e Oliveira (2010) os idosos têm muito a ensinar, porém ainda tem muito a aprender, demonstrando o quanto necessitam estar sempre em contato com novos conhecimentos e novas experiências. As autoras também destacam que estimular processos de aprendizagem significativa para esse público é importante por permitir a socialização, a inclusão no contexto contemporâneo, além de possibilitar a ampliação de suas relações interpessoais. Nesse sentido, a participação dos idosos em programas e ações de educação ambiental, além de resgatar as experiências vividas ao longo da vida, permite a sua inclusão acerca das questões socioambientais atuais fazendo com que se aproximem dos conhecimentos sobre tais problemas e que, assim, possam se envolver e participar de estratégias para transformar o ambiente em que vivem.

Fazendo uma aproximação entre a Política Nacional de Educação Ambiental (BRASIL, 1999) e a Política Nacional do Idoso (BRASIL, 1994) observamos que a última sugere a integração dos idosos na comunidade, valorizando sua memória e a transmissão de conhecimentos para os mais jovens, como meio de garantir a continuidade da identidade cultural. Já a primeira, destaca que um dos princípios da educação ambiental diz respeito à participação da sociedade como âncora de projetos preservacionistas. Nesse sentido, trazer o idoso para participar desses conflitos ambientais permite que ele possa colocar sua experiência de vida em prática (MACHADO; VELASCO; AMIM, 2006). Desta forma, não será apenas um espectador, mas um indivíduo ativo, exercendo seu papel de cidadão atuante nas questões ambientais.

$\mathrm{Na}$ sequência, questionamos as idosas se já haviam participado de alguma ação de educação ambiental em outros momentos de sua vida e, dentre 12 respostas obtidas, seis destacaram que nunca haviam atuado em ações de EA, enquanto outras seis disseram ter participado da edição anterior do Clube Tetéia e que decidiram retornar em 2014 para participar de outras atividades que o Clube iria desenvolver nesse ano.

Seguindo essa perspectiva de verificar a aproximação que os participantes tinham com a educação ambiental, perguntamos sobre suas concepções em relação a esse campo do conhecimento, a partir do seguinte questionamento "Cite cinco palavras que você acredita ter relação com a educação ambiental". Para compreender os resultados obtidos, fizemos uma revisão da literatura sobre concepções de educação ambiental, na qual identificamos um vasto campo de produção científica apresentado por diversos autores (SAUVÉ, 1995, 2005; SORRENTINO, 2005; REIGOTA, 2004; GUIMARÃES, 2004; SILVA, 2007; MARPICA, 2008; VALENTI, 2010; IARED, 2010; MARTINS, 2013, 2015). 
Guimarães (2004) aponta que a Educação Ambiental pode ser cunhada em dois paradigmas, sendo o primeiro apresentando um conceito de conservação da natureza sem se preocupar com as questões socioambientais e tendo no desenvolvimento tecnológico algumas alternativas para atingir a conservação do ambiente; e o segundo paradigma preocupado com a relação ser humano-natureza, atuando de forma crítica para promover a transformação social. Marpica (2008), a partir da revisão de literatura e com base nas categorias propostas por Silva (2007), orientou seus estudos na análise das tendências sobre educação ambiental contidas em livros didáticos nas diferentes disciplinas formulando quatro categorias: silenciosa, conservacionista, pragmática e crítica. Utilizando das mesmas categorias, Valenti (2010) e lared (2010) realizaram análises sobre tendências de educação ambiental nas práticas desenvolvidas em Unidades de Conservação e em concepções apresentadas por professoras da educação básica, respectivamente.

Ao observar os dados obtidos com as concepções apresentadas pelas idosas participantes, identificamos a tendência conservacionista (MARPICA, 2008) em todas as falas, uma vez que diversas participantes citaram palavras enfatizando a proteção ao mundo natural, as ações comportamentais e individuais para a superação da crise socioambiental e a ausência de questões que abordam a participação e o envolvimento coletivo como podemos observar em alguns trechos abaixo:

"Vida, educação, preservação do ambiente e da vida, poluição, ar; água”. Participante 2.

"Não poluir o meio ambiente, como: lixo, cigarro, rios, lagos, fumaça das fábricas, carros, etc". Participante 7.

"Reciclar, aproveitar tudo o que pode ser reciclado, não jogar lixo nas ruas, sempre manter a cidade limpa como se fosse a nossa própria casa". Participante 9.

"Não jogar papel e lixo na sua rua; reciclar; manter limpo lata de coleta de lixo; respeitar dias de coleta e horário". Participante 10.

Esses dados permitem realizar novas reflexões e trazem subsídios para repensar as práticas educativas que são desenvolvidas com o público idoso, uma vez que há necessidade de promover ações que caminhem para uma visão mais crítica e participativa de educação ambiental, valorizando os saberes éticos, estéticos e os conhecimentos desse grupo, a fim de ampliar as suas percepções e compreensões sobre o campo ambiental.

Por fim, tivemos o objetivo de compreender a função dos zoológicos na visão das participantes do Clube Tetéia, uma vez que a história dessas instituições é marcada por grandes transformações. Os zoológicos têm sua origem na Antiguidade, quando colecionar animais era uma prática comum aos 
imperadores da época, com a finalidade de lazer e principalmente de demonstração de status e poder. Com a expansão das cidades e do aumento do uso dos recursos naturais, que acarretaram na destruição do habitat de muitas espécies, começam a surgir a partir da década de 1950 novas tendências e objetivos para a criação e manutenção dos zoológicos, os quais passaram a contemplar princípios relacionados ao desenvolvimento de pesquisas na área de manejo e conservação da fauna; ao lazer e ao entretenimento; e à implementação de projetos e programas de educação ambiental (AURICCHIO, 1999; CONWAY, 1969, 1995, 2003; KNOWLES, 2003; MILLER et al., 2004; PATRICK; TUNNICLIFFE, 2012). Por ser uma transformação atual de tais paradigmas e perspectivas, é muito importante compreender as visões e percepções que visitantes e participantes de ações educativas apresentam sobre essas instituições, verificando se existe uma aproximação com os pilares e missões reais dos zoológicos na atualidade.

$\mathrm{Na}$ Tabela 2, podemos observar as categorias emergentes dessa temática que coincide com os pilares e as missões dos zoológicos modernos.

Tabela 2: Questionamento sobre a função dos zoológicos na visão das participantes.

Qual é a função dos zoológicos?

\begin{tabular}{|c|c|c|}
\hline $\begin{array}{l}\text { Frequência } \\
\text { de respostas }\end{array}$ & Categorias & Exemplos de citações \\
\hline 9 & $\begin{array}{l}\text { Preservação/ } \\
\text { Conservação }\end{array}$ & $\begin{array}{c}\text { "Proteger os animais que estão fora do seu habitat, } \\
\text { proporcionando-Ihes ambiente, alimentação próximos } \\
\text { ao que teriam no seu ambiente, cuidando da saúde e } \\
\text { bem estar dos animais (...)" Participante } 2 \text {. } \\
\text { "Conservação das espécies de animais em extinção, e } \\
\text { preservação e conservação de meio ambiente" } \\
\text { Participante } 4 .\end{array}$ \\
\hline 2 & $\begin{array}{l}\text { Conhecer os } \\
\text { animais }\end{array}$ & $\begin{array}{c}\text { "(...) possibilitar ao público conhecer animais selvagens, } \\
\text { aves, cobras" Participante } 2 . \\
\text { "Conhecermos e vermos animais selvagens" } \\
\text { Participante } 5 .\end{array}$ \\
\hline 2 & Lazer & $\begin{array}{c}\text { "(...) tem também a visita das pessoas. É um passeio } \\
\text { muito agradável" } \\
\text { Participante } 9 .\end{array}$ \\
\hline 2 & Educação & $\begin{array}{c}\text { "(...) tratar os animais, educar, respeitar os animais" } \\
\text { Participante } 12 . \\
\text { "(...) e que tenham um relacionamento com os visitantes } \\
\text { para a conservação do mesmo" Participante } 8 .\end{array}$ \\
\hline 1 & $\begin{array}{l}\text { Contato com a } \\
\text { natureza }\end{array}$ & $\begin{array}{l}\text { "(...) Para que as pessoas tenham mais contato com a } \\
\text { natureza e com os animais" Participante } 10 .\end{array}$ \\
\hline 1 & Não sabe & "Não sei" Participante 1. \\
\hline
\end{tabular}

Fonte: Autoria própria. 
Ao observar as concepções apresentadas pelas participantes do Clube Tetéia, identificamos que as categorias mais citadas dizem respeito à "Conservação e preservação", "Conhecer os animais silvestres", "Lazer" e "Educação", traçando uma relação direta com os princípios apontados pela World Association of Zoos and Aquariums (WAZA).

Além disso, em uma pesquisa desenvolvida em zoológicos e aquários de 19 países - inclusive no Brasil - com o objetivo de avaliar as concepções de seu público sobre biodiversidade e conservação, foi destacada a importância das visitas a essas instituições por fortalecerem os conhecimentos dos visitantes sobre a biodiversidade (MOSS et. al. 2014). O estudo reforça a importância dos zoológicos na conservação e também a eficácia de programas educativos que visam à formação de multiplicadores de conhecimentos ambientais (COSTA, 2004). Essa perspectiva permite incluir o Clube Tetéia em uma interface entre a educação ambiental e a inclusão de idosos, uma vez que aproxima os princípios da educação ambiental, como a formação de multiplicadores, com a valorização, inclusão, envolvimento e atuação dos idosos, contribuindo para um envelhecimento ativo e participativo (MACHADO; VELASCO; AMIM, 2006; CASSOL, 2012).

\section{Descrição das atividades desenvolvidas no Clube Tetéia - Edição 2014.}

O Clube Tetéia - Edição 2014, foco da investigação deste artigo, apresentou uma estrutura muito interessante e diferenciada em relação à edição anterior devido à inserção de novas áreas da FPZSP para o desenvolvimento de ações educativas com as idosas participantes.

Os encontros aconteceram de março a dezembro de 2014, contando inicialmente com uma palestra introdutória sobre a evolução dos zoológicos e da FPZSP e sobre seu Programa de Educação Ambiental. Na sequência, a cada mês (equivalente a dois encontros do Clube) as idosas tiveram a oportunidade de interagir com as atividades elaboradas pelas áreas que aceitaram participar do projeto, sendo elas a Divisão de Veterinária, o Setor de Répteis, o Zoo Safári, o Setor de Mamíferos, o Setor de Aves, o Setor de Gestão Ambiental e o Sistema de Gestão Integrada, a Fazenda do Zoo, o Setor de Alimentação Animal, o Programa de Enriquecimento Comportamental Animal e a Divisão de Engenharia (especificamente os setores de Ambiente e Manutenção). Nesse processo tivemos o envolvimento de diversos profissionais do parque, sendo que, muitos deles nunca haviam tido contato com atividades de educação ambiental durante sua rotina de trabalho. Esse fato contribui para solidificar as discussões e reflexões sobre a conservação da fauna, favorecendo a pluralidade de saberes e a troca intergeracional. 
Nas imagens abaixo (Figura 2) podemos observar alguns momentos do Clube Tetéia - Edição 2014.
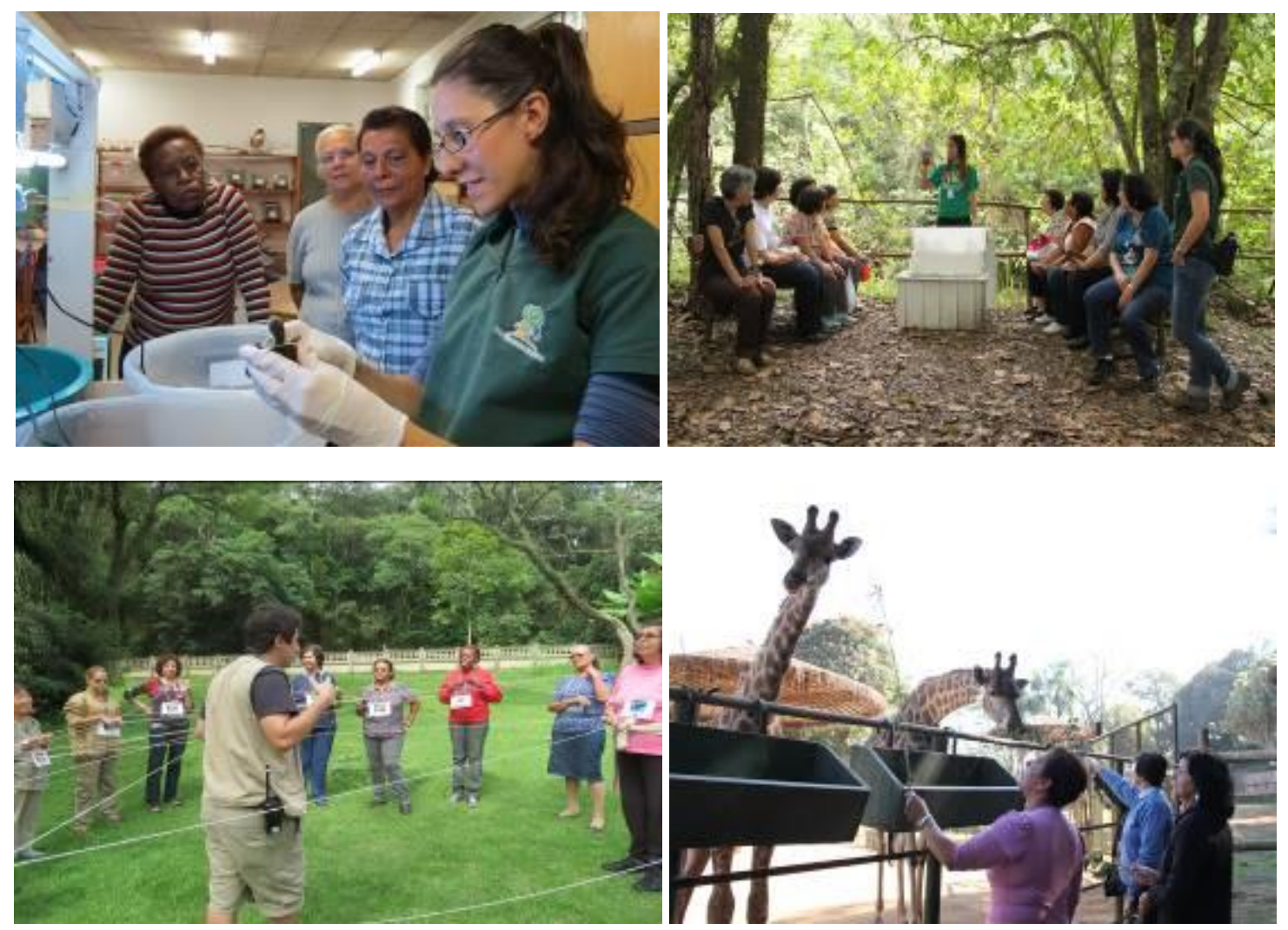

Figura 2: Imagens de alguns momentos do Clube Tetéia - Edição 2014.

Fonte: Arquivos da Fundação Parque Zoológico de São Paulo.

\section{Percepção do público participante sobre o processo educativo do Clube Tetéia - Edição 2014}

Ao final do Clube Tetéia - Edição 2014, realizamos um questionário procurando compreender a percepção das participantes em relação às contribuições desse projeto de educação ambiental desenvolvido pela Fundação Parque Zoológico de São Paulo. O primeiro questionamento diz respeito aos pontos positivos e negativos que os idosos identificaram ao longo do ano. Pontos negativos não foram citados. Os pontos positivos mencionados podem ser observados na Tabela 3 , a partir das seguintes categorias emergentes: 
Tabela 3: Questionamento sobre os pontos positivos do Clube Tetéia na visão das participantes Cite pontos positivos sobre o Clube Tetéia.

\begin{tabular}{|c|c|c|}
\hline $\begin{array}{l}\text { Frequência } \\
\text { de respostas }\end{array}$ & Categorias & Exemplos de citações \\
\hline 7 & $\begin{array}{l}\text { Conhecimento/ } \\
\text { Aprendizado }\end{array}$ & $\begin{array}{c}\text { "Conhecer e tirar muitas dúvidas. Foi ótimo". } \\
\text { Participante } 1 .\end{array}$ \\
\hline 6 & $\begin{array}{l}\text { Todas as } \\
\text { atividades }\end{array}$ & $\begin{array}{c}\text { "Todos os pontos foram positivos, foi um ótimo } \\
\text { aprendizado". Participante } 3\end{array}$ \\
\hline 2 & Novas amizades & $\begin{array}{c}\text { "São muitos, aprendi muito e fiz novas amizades". } \\
\text { Participante } 2 .\end{array}$ \\
\hline 1 & Vivência & $\begin{array}{l}\text { "Proporciona encontro com a natureza, respeito e } \\
\text { carinho pelos animais, plantas e todo meio ambiente } \\
\text { que nos rodeia, convívio saudável e alegre com os } \\
\text { técnicos do zoo e amizades novas". Participante } 8 \text {. }\end{array}$ \\
\hline
\end{tabular}

Fonte: Autoria própria.

Observamos com maior frequência respostas associadas ao processo de aprendizagem. Como afirma Scortegagna e Oliveira (2010), a educação não está presente somente em espaços formais, deste modo, todo indivíduo está passível de um processo educativo não formal, tornando-se indispensável à valorização de todas as formas de ensino e aprendizagem associadas à realidade. Além disso, a educação e a aprendizagem permanentes de homens e mulheres à medida que envelhecem e a oportunidade de desenvolverem novas habilidades estão previstas no documento "Envelhecimento Saudável Uma Política de Saúde" elaborado pela Unidade de Envelhecimento e Curso de Vida da Organização Mundial de Saúde (WORLD HEALTH ORGANIZATION, 2005).

$\mathrm{Na}$ sequência, questionamos qual a área técnica da FPZSP que mais haviam gostado de conhecer e ter contato no âmbito do Clube Tetéia. Diversas áreas foram apontadas como a preferida, porém, o que nos chama a atenção nessa questão são as justificativas, como a citação a seguir que faz menção à Estação de Tratamento de Água (ETA) presente na instituição, a qual faz parte do Setor de Gestão Ambiental (SEGEA):

"Foi da água, pois estamos vendo como está fazendo falta. Ainda bem que tem o reaproveitamento!" Participante 3.

O indivíduo associou a aprendizagem que obteve a um tema atual, o qual vem sendo vivenciando em seu dia-a-dia. Para Freire (2005) quando o processo de ensino-aprendizagem aproxima o educando da realidade na qual está inserido, tem-se uma tomada de consciência crítica, passando o indivíduo a se enxergar como parte do meio, levando-o a refletir sobre suas ações. Assim, a educação passa a desempenhar seu papel social, político e libertador. 
Além disso, fizemos o seguinte questionamento "De que maneira o Clube contribuiu para transformar sua vida?", procurando compreender como a atividade colaborou para uma maior qualidade de vida e envelhecimento ativo. Identificamos as seguintes categorias emergentes a partir dos dados apresentados (Tabela 4):

Tabela 4: Questionamento sobre a contribuição do Clube Tetéia para a transformação da vida das idosas participantes.

De que maneira o Clube Tetéia contribuiu para transformar sua vida?

\begin{tabular}{|c|c|c|}
\hline $\begin{array}{l}\text { Frequência } \\
\text { de respostas }\end{array}$ & Categorias & Exemplos de citações \\
\hline 6 & $\begin{array}{l}\text { Inclusão na } \\
\text { sociedade }\end{array}$ & $\begin{array}{c}\text { "Eu me sinto muito mais inserida no mundo, não como } \\
\text { espectadora, mas participante". Participante } 11 .\end{array}$ \\
\hline 5 & Aprendizado & $\begin{array}{c}\text { "Vários pontos positivos como aprendizado, } \\
\text { conhecimento ambiental, reaproveitamento da água, } \\
\text { esterco para terra, anuidade com o grupo". } \\
\text { Participante } 10 .\end{array}$ \\
\hline 5 & $\begin{array}{l}\text { Novas } \\
\text { Experiências/ } \\
\text { Vivência }\end{array}$ & $\begin{array}{c}\text { "Fiquei muito contente nos meus } 75 \text { anos plantei uma } \\
\text { árvore". Participante } 2 .\end{array}$ \\
\hline 3 & $\begin{array}{c}\text { Todas as } \\
\text { experiências } \\
\text { vividas no Clube } \\
\text { Tetéia }\end{array}$ & $\begin{array}{c}\text { "Mudou em tudo. Quero saúde para poder vir } \\
\text { novamente". Participante } 6 .\end{array}$ \\
\hline 1 & $\begin{array}{l}\text { Multiplicadores de } \\
\text { conhecimentos }\end{array}$ & $\begin{array}{c}\text { “(..) passar para as pessoas tudo que aprendi”. } \\
\text { Participação } 5 .\end{array}$ \\
\hline
\end{tabular}

Fonte: Autoria própria.

Podemos observar que a categoria "Inclusão na sociedade" apareceu com maior frequência, corroborando a perspectiva de Scortegagna e Oliveira (2010) quando dizem que o idoso precisa se sentir inserido e percebido na sociedade na qual vive. Uma educação permanente poderá modificar o pensamento do indivíduo de modo que permita um avanço tanto na estrutura social-democrática quanto nas relações interpessoais.

Destacamos também, a categoria "Novas Experiências/ Vivência", na qual uma participante demonstra o encantamento ao ter plantado uma árvore. A educação possibilita uma nova oportunidade de ação para o idoso, permitindoIhe não só repassar seu conhecimento adquirido com os anos, mas também de ter novas experiências, novos conhecimentos e novas vivências (SCORTEGAGNA; OLIVEIRA, 2010).

Outra categoria emergente interessante é a "Multiplicadores de conhecimentos". Nela a idosa afirmou que pretende passar para outros tudo o Revbea, São Paulo, V. 11, № 4: 269-288, 2016. 
que aprendeu no decorrer de sua participação no Clube, fato que caracteriza um dos objetivos fundamentais da educação ambiental, que é a disseminação de conhecimentos, e uma das finalidades do Clube, que é a troca intergeracional de experiências e saberes. Segundo a World Health Organization (2005), o aprendizado entre gerações preenche a lacuna entre as diferenças de idade, melhora a transmissão de valores culturais e promove a valorização de todas as idades.

Em relação à recordação de experiências já vividas, obtivemos com grande frequência respostas que ressaltavam a infância de alguns idosos, muitas das quais foram vivenciadas na zona rural e em contato com animais, uma vez que todas as atividades do Clube Tetéia aconteceram nas unidades da FPZSP que também estão inseridas em áreas verdes, fazendo com que essas memórias e lembranças viessem à tona (Figura 3). Algumas participantes também apontaram sua vivência enquanto estudantes, fazendo a relação entre sua formação escolar e os conhecimentos aprendidos durante o Clube em um contexto não escolar. Além disso, alguns causos e estórias que ouviam de seus pais também apareceram nos questionários aplicados.

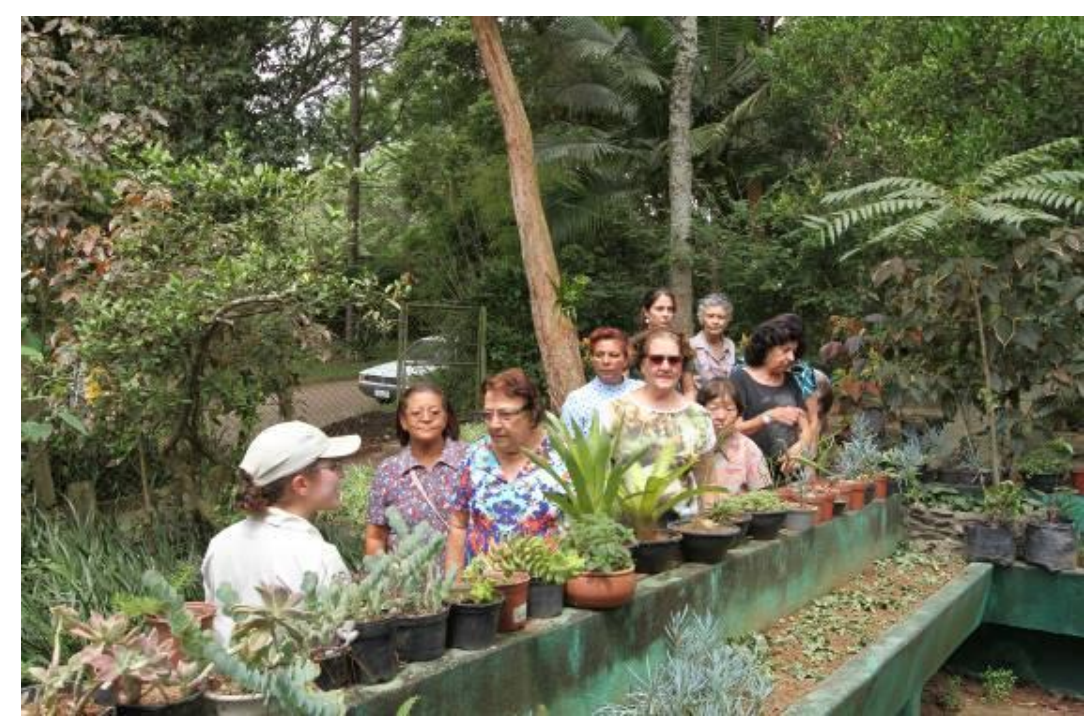

Figura 3: Exemplo de atividade desenvolvida pela equipe do Setor de Ambiente da FPZSP que proporciona a recordação de experiências vividas pelos idosos participantes.

Fonte: Paulo Gil/ Arquivo FPZSP

Partindo do princípio que a educação ambiental tem por objetivo fundamental a democratização do saber, no qual procura desenvolver uma compreensão integrada do meio em que vivemos, uma maneira de valorizar essa democratização é a disseminação dos saberes, sejam eles científicos ou populares. O idoso viveu e vive as transformações ambientais, sendo assim considerado um grande articulador de experiências vividas, como comportamentos do passado que, independente de serem considerados certos 
ou errados, possibilitaram trazer à discussão a problemática do atual contexto socioambiental (MACHADO; VELASCO; AMIM, 2006).

A interação social é muito importante quando falamos em educação ambiental para idosos. Um exemplo disso foi observado na questão: "Como foi o contato e troca de conhecimentos com a equipe técnica?". Somente pontos positivos foram relatados, conforme a citação abaixo:

"Eles tem muita paciência conosco, muito gentis, só tenho que agradecer" Participante 12.

A participante ressalta a atenção recebida, elogiando a paciência por parte da equipe técnica. Como aborda Scortegagna e Oliveira (2010), os idosos são por muitas vezes vítimas de opressão, seja ela exercida pela sociedade ou até mesmo pelo seu círculo familiar, por serem considerados sujeitos improdutivos e sem capacidade de aprendizado. Deste modo, a educação na terceira idade assume seu papel libertador. Como menciona Freire (2005), o diálogo crítico e libertador devem ser realizados com os oprimidos, permitindo um processo de reflexão onde o idoso terá condições de se permitir a uma nova aprendizagem e experiência.

Por fim, ao questionarmos se indicariam o Clube Tetéia para outras pessoas, todas as participantes responderam positivamente. $\mathrm{O}$ motivo mais sinalizado foi por conta do conhecimento e aprendizado que o projeto proporciona, como podemos evidenciar nessa citação:

"Indicaria com certeza porque os conhecimentos são ótimos". Participante 7.

Scortegagna e Oliveira (2010) afirmam que idosos necessitam estar em contato com novas experiências e conhecimentos, já que possuem muito a ensinar, porém ainda tem muito a aprender. Além disso, os fatores psicológicos, que incluem a inteligência e capacidade cognitiva (por exemplo, a capacidade de resolver problemas e de se adaptar a mudanças e perdas), são indícios fortes de envelhecimento ativo e longevidade. Durante o processo de envelhecimento normal, algumas capacidades cognitivas (inclusive a rapidez de aprendizagem e memória) diminuem, naturalmente, com a idade. Entretanto, essas perdas podem ser compensadas por ganhos em sabedoria, conhecimento e experiência (WORLD HEALTH ORGANIZATION, 2005). 


\section{Considerações finais}

No presente estudo tivemos o objetivo de discutir as potencialidades e oportunidades do Clube Tetéia - Edição 2014 a partir da percepção das idosas participantes, procurando contribuir para 0 aprimoramento de práticas educativas atreladas ao envelhecimento ativo dos idosos. Ao longo da trajetória da investigação, observamos que a principal expectativa das participantes em relação ao Clube Tetéia era a aprendizagem sobre conceitos, temáticas e questões ambientais, o que foi proporcionado ao final do processo educativo em 2014, cujas principais contribuições evidenciadas dizem respeito exatamente aos novos aprendizados e à inclusão social que esse projeto de educação ambiental promove.

Nesse sentido, o desenvolvimento de ações e projetos de educação ambiental para esse público em zoológicos apresenta potencialidades como proporcionar um ambiente de diálogo e troca de conhecimentos e aprendizagens sobre questões ambientais, promover a inclusão social dos idosos e estabelecer momentos de descontração e alegria que contribuem para um envelhecimento ativo e saudável. Além disso, os zoológicos constituem ambientes que possibilitam a interação das lembranças e memórias dos participantes com as questões ambientais atuais e uma grande oportunidade para a troca intergeracional, com diversos profissionais que atuam diretamente com o cuidado e bem-estar animal.

A partir das reflexões sobre esse projeto de educação ambiental desenvolvido na FPZSP e como forma de inspirar outros zoológicos e instituições similares a realizarem atividades voltadas ao público idoso, indicamos como sugestões para criação de espaços e ações educativas envolvendo idosos a busca por parcerias (por meio das Universidades Abertas, casas de repousos, associações de moradores, organizações religiosas, entre outros), a criação de condições apropriadas para atender o público, tanto em termos de infraestrutura quanto da própria programação da atividade, como a realização de encontros com curta duração e em lugares acessíveis, a valorização de conhecimentos e vivências de cada participante, a possibilidade dos idosos conhecerem a rotina e interagirem com os profissionais da instituição e, finalmente, o cuidado ao desenvolver atividades que envolvam a desmistificação de alguns conceitos e saberes, evitando possíveis constrangimentos e desvalorização dos conhecimentos populares.

\section{Agradecimentos}

À coordenação do Curso de Gerontologia da Escola de Artes, Ciências e Humanidades da Universidade de São Paulo (EACH/USP) e da Universidade Aberta da Terceira Idade (UnATI) pelo apoio, parceria e envolvimento para a realização e continuidade do "Clube Tetéia". 


\section{Referências}

AURICCHIO, A.L.R. Potencial da Educação Ambiental nos zoológicos brasileiros. Publicações avulsas do Instituto Pau-Brasil de História Natural, São Paulo, n. 1, p. 1-46, 1999.

BRASIL, Ministério da Educação. Política Nacional de Educação Ambiental, 1999.

BRASIL, Ministério do Desenvolvimento Social e Combate à Fome. Política Nacional do Idoso, 1994.

CASSOL, P.B. A gerontologia interface o meio ambiente como estratégia no cuidado e na promoção da saúde. Rev. Elet. Em Gestão, Educação e Tecnologia Ambiental, v. 6, n. 6, p. 1043-1048, 2012

COSTA G.O. Educação Ambiental - Experiências dos Zoológicos Brasileiros. Rev. eletrônica Mestr. Educ. Ambient. ISSN 1517-1256, Volume 13, julho a dezembro de 2004.

CONWAY, W.G. Zoos: their changing roles. Science, v. 163, p. 48-52, 1969.

CONWAY, W. G. Wild and zoo animal interactive management and habitat conservation. Biodiversity and Conservation, vol. 4, p. 573-594, 1995.

CONWAY, W.G. The role of zoos in the 21st century. International Zoo Yearbook, vol. 38, p. 7-13, 2003.

DIAS, R.S.; PIEPER, D.S. Educação Ambiental e terceira idade: uma reflexão sobre sustentabilidade através da história oral com idosos. Anais do XI Congresso Nacional de Educação. Pontifícia Universidade Católica do Paraná, Curitiba, 2013.

FREIRE, P. Pedagogia do Oprimido. Rio de Janeiro: Paz e Terra, 2005

GUIMARÃES, M. Educação Ambiental Crítica. In: LAYRARGUES, P.P. (coord.) Identidades da Educação Ambiental Brasileira. Brasília: Ministério do Meio Ambiente, 2004.

IARED, V.G. Concepções de educação ambiental e perspectivas pedagógicas de professoras do ensino fundamental e as potencialidades do Pólo Ecológico de São Carlos (SP).183f. 2010. Dissertação (Mestrado em Ecologia e Recursos Naturais). Centro de Ciências Biológicas e Saúde, Universidade Federal de São Carlos, São Carlos, 2010.

IBGE. Síntese de indicadores sociais: uma análise das condições de vida da população brasileira. Diretoria de Pesquisas. Coordenação de População e Indicadores Sociais, n. 27, 2010.

KNOWLES, J.M. Zoos and a century of change. The Zoological Society of London, v. 38, pp. 28-34, 2003. 
LEITE, T.T. Projeto Tetéia: inclusão de idosos na Fundação Parque Zoológico de São Paulo. 87fl. Trabalho de Conclusão do Programa Aprimoramento Profissional da Fundação Parque Zoológico de São Paulo. São Paulo, 2012.

LÜDKE, M.; ANDRÉ, M.E.D.A. Pesquisa em educação: abordagens qualitativas. São Paulo: EPU, 1986. 99 p.

MACHADO R.F.O.; VELASCO F.L.C.G.; AMIM V. O Encontro da Política Nacional da Educação Ambiental com a Política Nacional do Idoso. Saúde e Sociedade v.15, n.3, p.162-169, set-dez 2006.

MARPICA, N.S. As questões em livros didáticos de diferentes disciplinas da quinta série do ensino fundamental. 169f. 2008. Dissertação (Mestrado em Educação). Centro de Educação e Ciências Humanas, Universidade Federal de São Carlos, São Carlos, 2008.

MARTINS, C. Biodiversidade e Educação Ambiental: concepções e construção participativa de uma proposta educativa (Ensino Fundamental II, São Carlos SP). São Carlos: Universidade Federal de São Carlos, 2013. Monografia.

MARTINS, C.; OLIVEIRA, H.T. Biodiversidade no contexto escolar: concepções e práticas em uma perspectiva de educação ambiental crítica. Revista Brasileira de Educação Ambiental, v. 10, n. 1., p. 127-145, 2015.

MILLER, B. et al. Evaluating the conservation mission of zoos, aquariums, botanical gardens, and natural history museum. Conservation Biology, n. 1, vol. 18, 2004.

MORAES, R. Uma tempestade de luz: a compreensão possibilitada pela análise textual discursiva. In: Metodologias emergentes de pesquisa em educação ambiental. GALIAZZI, M.C.; FREITAS, J.V. (org.), 2 ed., ljuí: Ed. Unijuí, 2007, p. 85 -114.

MOSS et. al. Evaluating the contribution of zoos and aquariums to Aichi Biodiversity Target 1. Conservation Biology, Volume 29, No. 2, 537-544, 2014.

PATRICK, P.G.; TUNNICLIFFE, S. D. Zoo Talk. Springer, 2012.

PEREIRA, R.J. et al. Contribuições dos domínios físico, social, psicológico e ambiental para a qualidade de vida global de idoso. Revista Psiquiatria, v. 28, n. 1, p. 27-38, 2006.

RANCURA, K.G.O. et al. Clube Tetéia: promovendo a participação de idosos em atividades da Fundação Parque Zoológico de São Paulo (FPZSP). Anais do XX Congresso da Associação Latino-americana de Zoológicos e Aquários, São Paulo, 2013.

REIGOTA, M. Meio ambiente e representação social. São Paulo: Cortez, 2004. 
RIO DE JANEIRO. Tratado de educação ambiental para sociedades sustentáveis e responsabilidade global, 1992. Disponível em: http://portal.mec.gov.br/secad/arquivos/pdf/educacaoambiental/tratado.pdf.

Acesso em: maio de 2015.

SAUVÉ, L. La Educación Ambiental entre la modernidad y la posmodernidad: en busca de um marco de referencia educativo integrador. Tópicos en Educación Ambiental, v. 1, n. 2, p. 7-25, 1999.

SAUVÉ, L. Una cartografia de corrientes em Educación Ambiental. In: SATO, M.; CARVALHO, I. (Orgs.) A pesquisa em educação ambiental: cartografias de uma identidade narrativa em formação. Porto Alegre: Artmed, 2005.

SCORTEGAGNA P.A.; OLIVEIRA R.C.S. Educação: integração, inserção e reconhecimento social para o idoso. Revista Kairós Gerontologia, 13 (1), São Paulo, junho 2010: 53-72.

SILVA, R.L.F. O meio ambiente por trás da tela: estudo das concepções de educação ambiental dos filmes da TV ESCOLA. 2007. 277f. Tese (Doutorado em educação). Faculdade de Educação da Universidade de São Paulo, São Paulo: 2007.

SORRENTINO, M. Educação ambiental e universidade: um estudo de caso. Tese (Doutorado em Educação), Universidade de São Paulo, São Paulo. 1995.

TRIVIÑOS, A.N.S. Introdução à pesquisa em ciências sociais: a pesquisa qualitativa em educação. São Paulo: Editora Atlas, 1987. 175 p.

VALENTI, M.W. Educação ambiental e biodiversidade em unidades de conservação: mapeando tendências. 99f. 2010. Dissertação (Mestrado em Ecologia e Recursos Naturais). Centro de Ciências Biológicas e Saúde, Universidade Federal de São Carlos, São Carlos, 2010.

WORLD HEALTH ORGANIZATION. Envelhecimento ativo: uma política de saúde. Tradução Suzana Gontijo. Brasília: Organização Pan-Americana da Saúde, 2005, 60p. 